\title{
Crescimento inicial de plantas de pequi após aplicação de 2,4-D
}

\author{
Cássio Jardim Tavares ${ }^{1}$, Leandro Spíndola Pereira ${ }^{2}$, Alana Cristina Ferreira Araújo², Deborah Amorim Martins ${ }^{2}$, Adriano Jakelaitis ${ }^{2}$ \\ ${ }^{1}$ Instituto Federal Goiano, Campus Posse, Rua Correntina, n. 824, Setor Dom Prudêncio, CEP 73900-000, Posse, GO, Brasil \\ ${ }^{2}$ Instituto Federal Goiano, Campus Rio Verde, Rod. Sul Goiana, Km 01, Zona Rural, C P 66, CEP 75901-970, Rio Verde, GO, Brasil
}

"Autor correspondente:

adriano.jakelaitis@ifgoiano.edu.br

Termos para indexação:

Fitotoxicidade

Herbicidas

Hormese

Index terms:

Phytotoxicity

Herbicide

Hormesis

Histórico do artigo:

Recebido em 31/5/2016

Aprovado em 27/03/2017

Publicado em 31/03/2017

doi: 10.4336/2017.pfb.37.89.1280

\begin{abstract}
Resumo - O ácido 2,4-diclorafenóxacético (2,4-D) tem causado efeitos tóxicos em várias culturas cultivadas vizinhas ao local na qual foi destinado, devido à deriva durante sua aplicação. Objetivou-se, nesta pesquisa, avaliar o efeito da deriva simulada por meio de subdoses do herbicida 2,4-D em plantas de pequi (Caryocar brasiliense, Camb.). Testaram-se em blocos completos casualizados com seis repetições as doses de $0 ; 1,67$; 3,$35 ; 6,70 ; 16,75 ; 33,50 ; 67,00$ e $134,00 \mathrm{~g} \mathrm{ha}^{-1}$ de equivalente ácido do herbicida. A unidade experimental foi de um vaso contendo uma planta de pequi. A aplicação de 2,4-D causou sintomas leves de epinastia nas folhas, com valores entre 6,25 e 13,33\% de fitointoxicação nas plantas de pequi; contudo, ocorreu a recuperação das plantas a partir dos 15 dias após a aplicação. Foi observado efeito hormético para as variáveis área foliar, área foliar específica e razão de área foliar. Porém, com o aumento das doses, verificou-se redução no crescimento das mudas, caracterizada pela diminuição nas variáveis foliares e massa seca total das plantas. Comparado ao controle (dose zero) foram observados maiores valores da partição de fotoassimilados para a parte aérea das plantas.
\end{abstract}

\section{Initial growth of Caryocar brasiliense plants after application of 2,4-D}

\begin{abstract}
The 2,4-dichlorophenoxy acid (2,4-D) causes toxic effects on various cultivated crops surrounding the place in which it is sprayed due to drift. This work evaluated low doses of 2,4-D herbicide in simulated drifting on Caryocar brasiliense, Camb. seedlings. They were tested in a randomized complete block design with six replications, using herbicide acid equivalent doses of $0 ; 1.67,3.35,6.70,16.75$, $33.50,67.00$ and $134.00 \mathrm{~g} \mathrm{ha}^{-1}$. The experimental unit was a vessel containing one $C$. brasiliense plant. The application of 2,4-D caused low epinasty in leaves with values between 6.25 to $13.33 \%$ phytotoxicity in C. brasiliense. However, there was full recovery of the plants 15 days after application. Hormesis effect was observed for leaf area, specific leaf area and leaf area ratio variables. However, with increasing doses there were reductions in seedlings growth characterized by reduction in leaf variables and plants total dry matter. Compared to control (zero dose) higher values of assimilates partition for aerial part of the plants were observed.
\end{abstract}

\section{Introdução}

A intensificação do uso de agrotóxicos e de fertilizantes, principalmente em lavouras de soja, milho, cana-deaçúcar e algodão, tem ocorrido devido à crescente ampliação da área agrí́cola no Cerrado e isto tem mudado a composição florística deste bioma (Soares \& Porto, 2007; Costa et al., 2012). O uso de herbicidas, como o 2,4-D, que atuam provocando distúrbios diversos, como crescimento anormal de tecidos, obstrução do floema, 
morte do sistema radicular, epinastia das folhas, e outras alterações, induzem as plantas sensíveis à morte, caso ocorra deriva, quando de sua aplicação (Fagliari et al., 2005) e podem interferir no crescimento e no desenvolvimento de plantas nativas.

Contudo, o uso de substâncias consideradas tóxicas, em doses muito menores que a utilizada para estimular o desenvolvimento vegetal, é conhecido como "hormese" (Calabrese \& Baldwin, 2002). Inicialmente, vários herbicidas foram desenvolvidos como reguladores de crescimento, comprovando a hipótese de hormese. Como exemplo, tem-se o 2,4-D, originalmente desenvolvido como auxina e que, em doses elevadas, tem efeito herbicida (Mousdale \& Coggins, 1991). Cedergreen et al. (2005) comentam que plantas cultivadas ou nativas submetidas a doses baixas de herbicidas revelam efeito hormético, com incrementos na variável dependente de poucos pontos percentuais à valores superiores a $100 \%$.

Os danos causados pelo herbicida em deriva dependem da concentração e da quantidade do princípio ativo que atinge as culturas (Cedergreen et al., 2009). Apesar dos prejuízos que a deriva de herbicidas pode proporcionar à produção agrícola, alguns pesquisadores constataram efeito estimulante no crescimento de diversas espécies cultivadas (Gitti et al., 2011; Silva et al., 2012) e nativas (Gusmão et al., 2011; Pereira et al., 2015) após a aplicação de subdoses de glyphosate.

O pequizeiro é uma importante planta nativa no bioma Cerrado que pertence à família Caryocaraceae e ao gênero Caryocar. Apesar das várias utilidades e da significativa área geográfica onde a espécie é explorada, não existe cultivo comercial de pequizeiro e a sua exploração ainda é puramente extrativista. Mesmo assim, gera emprego e renda no período de safra, e exerce importante papel na socioeconomia de muitas localidades de diferentes regiões do Brasil (Santos et al., 2013).

Além da importância na alimentação humana, o pequizeiro pode ser utilizado na reconstituição da vegetação nativa (Alves Júnior et al., 2015). No entanto, em áreas de recomposição da vegetação nativa, ou em áreas de ocorrência natural do pequizeiro nota-se que áreas circunvizinhas podem ser canaviais, áreas de produção de culturas temporárias como milho, soja e arroz, bem como pastagens, onde o 2,4-D é comumente utilizado, caracterizando áreas particularmente sensíveis à deriva (Boutin et al., 2014; Egan et al., 2014).

No entanto, pouco se sabe sobre os efeitos do herbicida no crescimento e no desenvolvimento de plantas desta espécie. Assim, este trabalho objetivou avaliar o efeito da deriva simulada por meio de subdoses do herbicida 2,4-D em plantas de pequi (Caryocar brasiliense).

\section{Material e métodos}

As mudas de Caryocar brasiliense Camb. foram obtidas de viveiro procedente do Município de Guapó, GO. A pesquisa foi conduzida em condições de casa de vegetação climatizada no período de fevereiro a julho de 2014 no Instituto Federal de Educação, Ciência e Tecnologia Goiano, em Rio Verde, GO, sob as coordenadas $17^{\circ} 48^{\prime}$ e $67^{\prime \prime} \mathrm{S}$ e $50^{\circ} 54^{\prime} 18^{\prime}$ 'W e altitude de $754 \mathrm{~m}$.

As mudas foram selecionadas do mesmo lote com altura média de $20 \mathrm{~cm}$ e, posteriormente, foram transplantadas para vasos com capacidade volumétrica para $8 \mathrm{~L}$. Os vasos foram preenchidos com terra de subsolo. O substrato foi analisado e apresentou os seguintes atributos físico-químicos: $\mathrm{pH}$ em $\mathrm{CaCl}_{2}$ de 5,6; 22,84 $\mathrm{mg} \mathrm{dm}^{-3}$ de P; $190 \mathrm{mg} \mathrm{dm}^{-3}$ de K; 5,98 $\mathrm{cmol}_{\mathrm{c}} \mathrm{dm}^{-3}$ de $\mathrm{Ca} ; 1,80 \mathrm{cmol}_{\mathrm{c}} \mathrm{dm}^{-3} \mathrm{de} \mathrm{Mg} ; 2,80 \mathrm{cmol}_{\mathrm{c}} \mathrm{dm}^{-3} \mathrm{de} \mathrm{H}+\mathrm{Al}$; 2,45 dag kg-1 $^{-1}$ de matéria orgânica e $74,7 \%$ de saturação por bases. O substrato de cada vaso foi fertilizado com $50 \mathrm{~g}$ de superfosfato simples e $10 \mathrm{~g}$ de cloreto de potássio. Após o transplante da muda, a cada 30 dias foi adicionado $1 \mathrm{~g}$ por vaso de fertilizante, contendo, em porcentagem, $\mathrm{N}=13, \mathrm{P}_{2} \mathrm{O}_{5}=5, \mathrm{~K}_{2} \mathrm{O}=13, \mathrm{~B}=0,04$, $\mathrm{Ca}=1,0, \mathrm{Cu}=0,05, \mathrm{~S}=5,0, \mathrm{Fe}=0,2, \mathrm{Mg}=1,0 ; \mathrm{Mn}=$ $0,08, \mathrm{Mo}=0,005$ e $\mathrm{Zn}=0,15$.

Aos 40 dias do transplantio, as mudas foram agrupadas por tamanho para a padronização dos blocos. Os tratamentos corresponderam à deriva simulada de sete doses do herbicida 2,4-D: 1,$67 ; 3,35 ; 6,70$; 16,$75 ; 33,50 ; 67,00$ e $134,00 \mathrm{~g} \mathrm{ha}^{-1}$, correspondentes a 0,$25 ; 0,50 ; 1,00 ; 2,50 ; 5,00 ; 10,00$ e $20,00 \%$ da dose comercial recomendada de $670 \mathrm{~g} \mathrm{~L}^{-1}$ de equivalente ácido. Como controle, foi avaliado um tratamento sem herbicida. O delineamento utilizado foi o de blocos completos casualizados, com seis repetições. A unidade experimental foi de um vaso contendo uma planta de pequi.

A deriva simulada consistiu da aplicação do herbicida 2,4-D (DMA $806 \mathrm{BR}^{\circledR}, 670 \mathrm{~g} \mathrm{~L}^{-1}$ ) utilizando um pulverizador costal com pressão constante mantida por $\mathrm{CO}_{2}$ comprimido, equipado com barra de quatro pontas de pulverização e bico da série XRTeejet ${ }^{\circledR}$, 
tipo leque modelo XR11002-VP. Foram aplicados $120 \mathrm{~L} \mathrm{ha}^{-1}$ de calda. As plantas foram colocadas fora da casa de vegetação e no momento da aplicação a temperatura máxima foi de $19,0{ }^{\circ} \mathrm{C}$, a velocidade do vento de $0,9 \mathrm{~m} \mathrm{~s}^{-1}$ e a umidade relativa de $85 \%$. Após a aplicação do herbicida, os vasos foram transferidos para o interior da casa de vegetação.

A fitointoxicação das plantas de pequi foi avaliada aos 7, 15, 30 e 45 dias após a aplicação (DAA) do 2,4-D, com base na presença ou ausência de sintomas visuais, como clorose, epinastia e encarquilhamento das plantas. A fitointoxicação foi determinada por três avaliadores que aferiram visualmente os sintomas nas plantas, utilizando como padrão de comparação as plantas do tratamento controle. As notas foram expressas na forma de porcentagem, em que 0 (zero) indicou a ausência de quaisquer injúrias e 100 (cem) a morte completa das plantas.

No final do período experimental, aos 60 DAA, foi determinada a área foliar (AF), pelo método da soma do comprimento das nervuras principais dos folíolos (Oliveira et al., 2002), e aplicados os valores à equação 1. O comprimento das nervuras foi obtido com auxílio de uma régua milimetrada.

$$
\mathrm{AF}=1,218-0,012 \mathrm{~S}+0,0208 \mathrm{~S}^{2}
$$

Sendo: S a soma das nervuras dos folíolos.

Após a determinação da área foliar, os órgãos da planta (folhas, caules e raízes) foram separados/ acondicionados, em sacos de papel e colocados em estufa de circulação forçada de ar a $65^{\circ} \mathrm{C}$ até atingir peso constante, quando foram pesados. Com estes resultados, foram obtidas as alocações de massa seca para as folhas, caules e raízes pela relação destas com a massa seca total da planta. Foi determinada também a relação raiz/parte aérea pela divisão da massa seca de raízes pela soma das massas seca de folhas e caules.

Com os dados da massa seca e da área foliar foram determinadas também a razão de área foliar (RAF), pela divisão da AF pela massa seca total da planta; a área foliar específica (AFE), pela divisão da AF pela massa seca de folhas; e a razão de peso foliar (RPF), pela divisão da massa seca das folhas pela massa seca de toda a planta (Rodrigues et al., 2008).

Os resultados foram submetidos à análise de variância (ANOVA) pelo teste $\mathrm{F}$ e ajustados aos modelos de regressão, adotando-se o nível de significância de $5 \%$. Os modelos foram escolhidos pela simplicidade, significado biológico e pelo coeficiente de determinação. As análises estatísticas foram realizadas utilizando-se o programa estatístico Assistat (versão 7.7) e pelo software Sigmaplot v.12 (Sigmaplot, 2012). Os resultados significativos não ajustados aos modelos lineares ou não lineares foram representados por gráficos de linhas, ajustando no mesmo a diferença mínima significativa (LSD) a $5 \%$.

\section{Resultados}

Foram observados sintomas visuais de fitointoxicação do herbicida 2,4-D sobre as plantas de pequi aos 7 DAA e foram manifestados efeitos nas maiores doses testadas (Tabela 1). Contudo, os sintomas ocorreram somente na primeira semana após a aplicação e não houve progresso na evolução dos mesmos, desaparecendo a partir dos 15 DAA. A fitointoxicação visual aparente foi considerada leve, ocorrendo nas folhas novas e caracterizadas por epinastia das folhas, não sendo observados sintomas de clorose, necrose ou queda das mesmas.

Os valores de matéria seca de folhas e a massa seca total das plantas de pequi (Figuras 1a e 1b) apresentaram diminuição de forma linear em relação à dose de 2,4$\mathrm{D}$ aplicada, não sendo observado efeito de hormese para essas variáveis, mas redução de 0,015 e $0,020 \mathrm{~g}$ de massa seca por planta, quando expostas às doses reduzidas de 2,4-D. A massa seca de raízes e de caule não foram influenciadas pela deriva simulada do produto, apresentando médias de 7,49 e 6,12 g, respectivamente.

Tabela 1. Fitointoxicação média de plantas de pequi submetidas à deriva simulada do herbicida 2,4-D aos 7, 15, 30 e 45 dias após a aplicação (DAA)

\begin{tabular}{ccccc}
\hline \multirow{2}{*}{$\begin{array}{c}\text { Doses } \\
\left(\mathbf{g ~ h a}^{-1}\right)\end{array}$} & \multicolumn{4}{c}{ Fitointoxicação (\%) } \\
\cline { 2 - 5 } & 7 DAA & 15 DAA & 30 DAA & 45 DAA \\
\hline 0 & 0,00 & 0 & 0 & 0 \\
1,675 & 7,92 & 0 & 0 & 0 \\
3,35 & 6,25 & 0 & 0 & 0 \\
6,7 & 9,58 & 0 & 0 & 0 \\
16,75 & 12,92 & 0 & 0 & 0 \\
33,5 & 12,08 & 0 & 0 & 0 \\
67 & 10,83 & 0 & 0 & 0 \\
134 & 13,33 & 0 & 0 & 0 \\
\hline
\end{tabular}

*Modelo de regressão aos 7 DAA, $\left.\hat{Y}=0,0459+\left(13,4145 /\left(1+(\mathrm{x} / 1,7045)^{-0,6782}\right)\right)\right)$, $\mathrm{R}^{2}=0,9149$. 
A

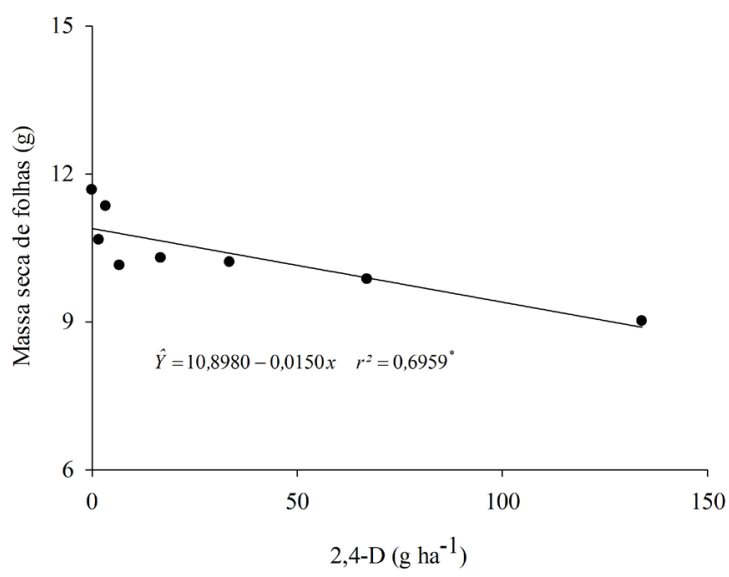

B

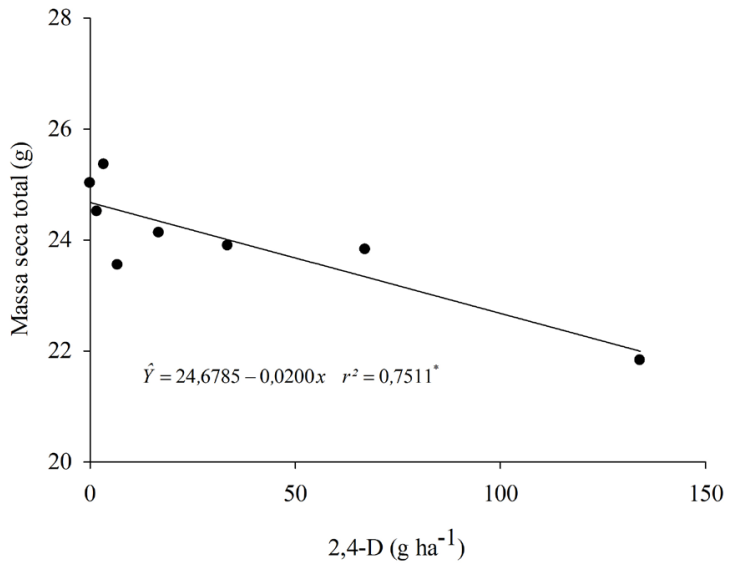

Figura 1. Massa seca de folhas (A) e massa seca total (B) de plantas de pequi em consequência da deriva simulada do herbicida 2,4-D, aos 60 dias após a aplicação.

Com relação à área foliar, verificou-se efeito significativo promovido pela deriva simulada do herbicida 2,4-D, sendo que na dose de 3,3 $\mathrm{g} \mathrm{ha}^{-1}$ ou $0,5 \%$ da dose comercial foi observado efeito de hormese, representando $20,7 \%$ de aumento nesta variável em relação ao controle (Figura 2a). Efeito herbicida foi observado a partir da dose de 33,5 $\mathrm{g} \mathrm{ha}^{-1}$ de 2,4-D, contudo não foi possível ajustar modelos de regressão para explicar a resposta biológica. Aárea foliar específica (AFE) apresentou também resposta diferencial em relação às doses de deriva simulada do herbicida 2,4$\mathrm{D}$, apresentando hormese a partir da dose de 1,675 até $33,5 \mathrm{~g} \mathrm{ha}^{-1}$ e efeito herbicida a partir desta dose (Figura $2 b)$.
A

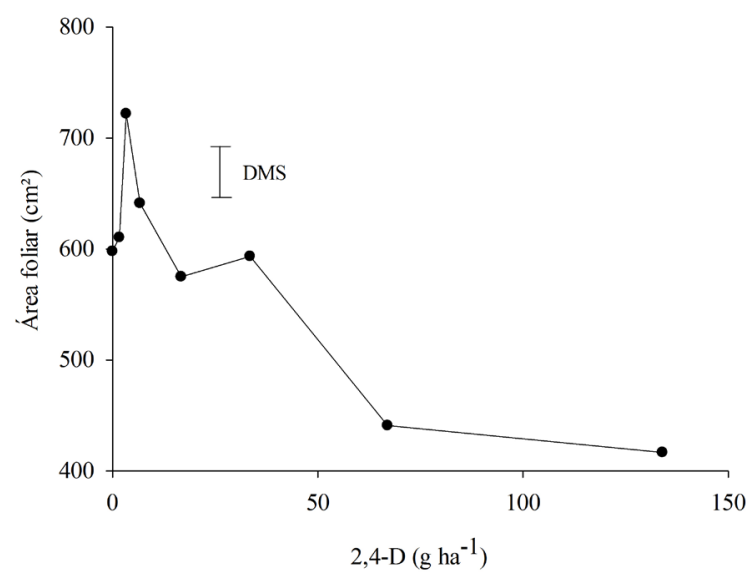

$\mathrm{B}$

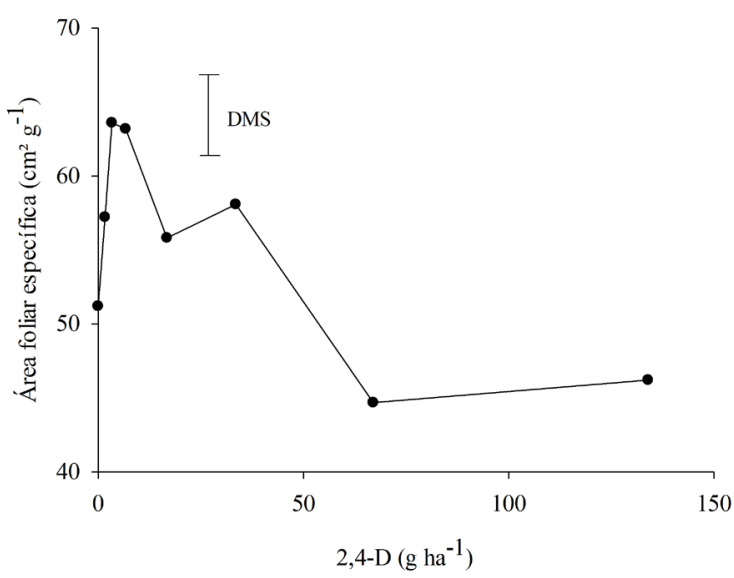

Figura 2. Área foliar (A) e área foliar específica (B) em folhas de plantas de pequi expostas à deriva simulada do herbicida 2,4-D, aos 60 dias após a aplicação.

Outro índice fisiológico do crescimento afetado pelas doses reduzidas de 2,4-D foi a razão de área foliar (RAF) que apresentou hormese nas doses de 3,35 e de $6,70 \mathrm{~g} \mathrm{ha}^{-1}$, que representou acréscimos de 19,12 e $13,95 \%$, respectivamente, em relação ao controle (Figura 3a). Semelhantemente aos resultados encontrados para área foliar (AF) e área foliar específica (AFE) não foram ajustados modelos de regressão. O efeito herbicida para RAF manifestou-se a partir da dose de 33,50 $\mathrm{g} \mathrm{ha}^{-1}$ de 2,4-D. A razão de peso foliar (RPF) apresentou resposta exponencial decrescente em relação ao aumento da dose de 2,4-D utilizada como deriva simulada (Figura 3b). 

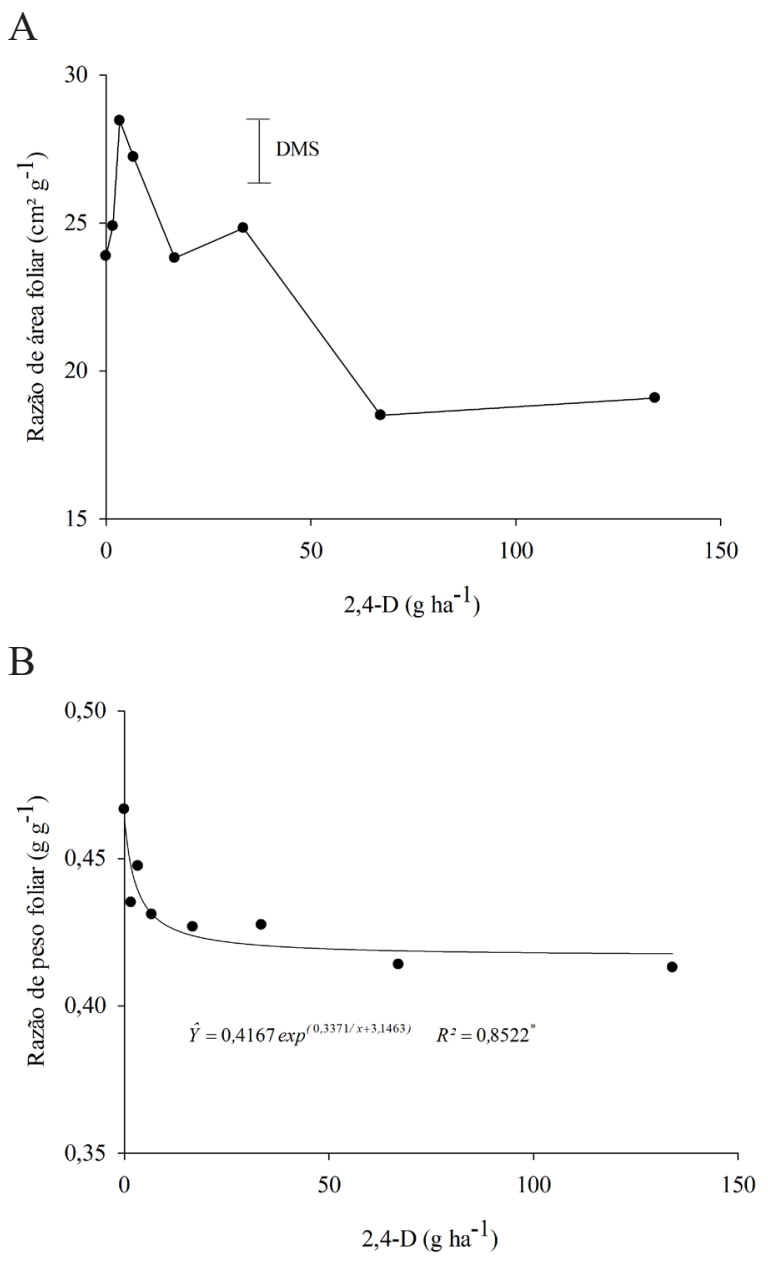

Figura 3. Razão de área foliar (A) e razão de peso foliar (B) em folhas de plantas de pequi expostas à deriva simulada do herbicida 2,4-D, aos 60 dias após a aplicação.

Quanto à relação raiz / parte aérea, com base na matéria seca, verificou-se aumento inicial na variável e depois estabilização (Figura 4). O aumento da relação ocorreu provavelmente devido à redução na quantidade de matéria seca da parte aérea, pois nota-se que a massa seca das raízes manteve-se praticamente constante em relação às doses do herbicida 2,4-D aplicadas (Figura 5).

Observa-se que a distribuição de massa seca para os diferentes órgãos das plantas de pequi apresentou pequena variabilidade com as doses do herbicida 2,4$\mathrm{D}$ decorrentes da deriva (Figura 5). A porcentagem de massa direcionada para as raízes ficou entre 28,63 e $32,45 \%$, para o caule entre 24,6 e $27,1 \%$ e para as folhas variou entre 41,3 e $46,7 \%$. Pelos resultados, demonstrase que as plantas jovens de pequi alocam a maior parte de sua produção de massa seca para as folhas, e que essa variável foi influenciada pelas doses do 2,4-D testadas.

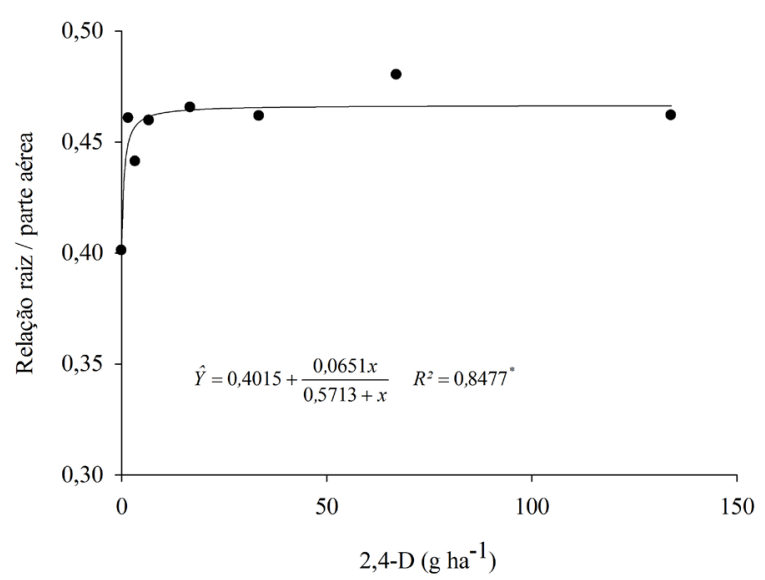

Figura 4. Relação raiz / parte aérea de plantas de pequi expostas à deriva simulada do herbicida 2,4-D, aos 60 dias após a aplicação.

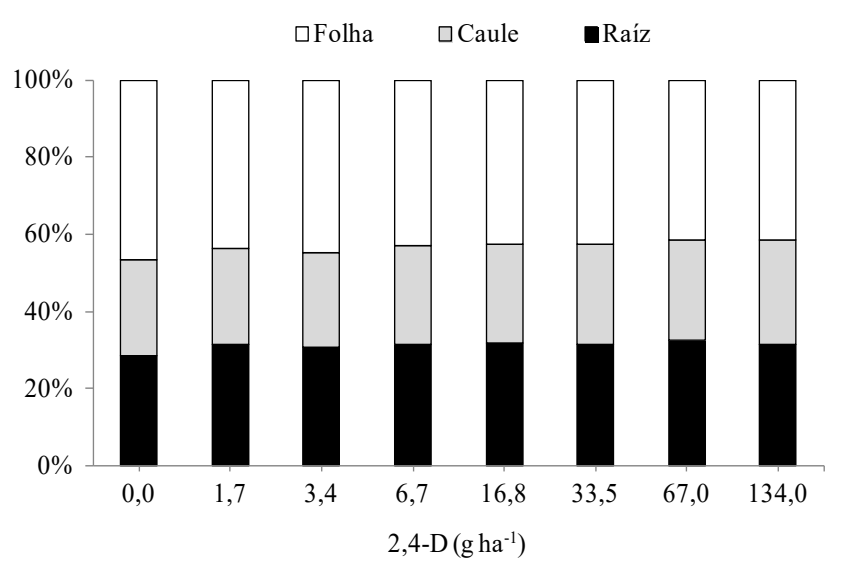

Figura 5. Proporções relativas dos órgãos (raízes, caule e folhas) em plantas de pequi expostas à deriva simulada do herbicida 2,4-D, aos 60 dias após a aplicação.

\section{Discussão}

São comuns os relatos de injúrias em culturas anuais ou perenes promovidas pela deriva da aplicação do herbicida 2,4-D. Nesta pesquisa, a fitointoxicação leve e temporária assemelhou-se a ausência de sintomas visuais causados por fitointoxicação de 2,4-D relatado por Constantin et al. (2007), em estudos de tolerância da molécula na cultura do fumo.

A fitotoxicidade do 2,4-D pode variar nas plantas desde uma leve epinastia nas folhas, seguida pela deformação até a morte da planta (Yamashita et al., 2013). Epinastia das folhas e deformações de ramos jovens e de folhas foram relatados quando ocorreu a aplicação de subdoses de 2,4-D na cultura da uva Itália 
(Oliveira Junior et al., 2007). Aplicando-se o herbicida 2,4-D para o controle de plantas daninhas em aplicações dirigidas na cultura do café, os sintomas de fitotoxidez no cafeeiro e o abortamento de frutos jovens também foram reportados por Ronchi et al. (2005). Segundo esses autores, os efeitos foram mais prejudiciais em plantas jovens e nas doses mais altas do produto.

Estudos realizados por Pereira et al. (2015) em plantas de pau-viola (Cyntharexyllum myrianthum) e araçáamarelo (Psidium cattleyanum), testando diferentes doses de glyphosate, evidenciaram que doses reduzidas do herbicida podem induzir a um maior crescimento de plantas (hormese), promovendo aumento de massa da matéria seca que pode culminar em maior área fotossintética, possibilitando crescimento mais rápido e, assim, propiciar uma rápida ocupação do nicho ecológico. No pequizeiro, nas menores doses do 2,4-D, foi observado o efeito hormético para as variáveis área foliar, razão de área foliar (RAF) e área foliar específica (AFE); porém, o acréscimo observado nestas variáveis não refletiu em incremento na massa seca das folhas (Figura 1a).

A área foliar é considerada uma característica referencial associada ao processo de capacitação de energia responsável pela produção de matéria orgânica e, consequentemente, pelo crescimento da planta. Reis et al. (2010) relatam que o 2,4-D apresenta desempenho similar ao da auxina, desencadeando a aceleração do metabolismo de ácidos nucléicos, podendo explicar o comportamento observado de hormese em baixas doses e um efeito desfavorável nas maiores doses.

Considerando-se o efeito na RAF, evidencia-se que o particionamento de assimilados para as folhas em relação à massa seca total produzida pela planta foi afetado pelo uso do herbicida. A RAF pode decrescer em função da diminuição da área foliar útil e significa que progressivamente a quantidade de assimilados destinados às folhas foi diminuída (Castro et al., 2003).

Por outro lado, o aumento da relação raiz / parte aérea é apresentado como uma reação da planta ao estresse, seja aumentando a formação de massa das raízes, de modo a explorar maior volume de solo para melhorar a absorção de água e nutrientes, ou diminuindo o acúmulo de matéria seca na parte aérea, o que possibilita redução da área de transpiração (Sá et al., 2013), acreditandose ter ocorrido esta última situação com o pequizeiro, sobretudo porque houve redução na área foliar das plantas nas maiores dosagens (Figura 2a).
Pesquisas realizadas por Silva (2015) confirmaram que os herbicidas 2,4-D e nicosulfuron causaram efeitos em plantas de baru (Dipteryx alata), árvore típica do Cerrado brasileiro, com alterações na fisiologia e no metabolismo das plantas, como a maior atividade das enzimas do sistema antioxidante de defesa e o aumento na concentração de peróxido de hidrogênio e de malonaldeído.

Os resultados apresentados confirmam que o 2,4-D, mesmo em doses baixas, pode promover alterações nas características morfofisiológicas das plantas de pequi. Relacionado às menores doses, a área foliar e as variáveis correlacionadas a ela foram as mais sensíveis (Figuras 2a, 2b e 3a), sugerindo que em condições naturais podem ocorrer danos, limitando a fisiologia e a produtividade vegetal desta espécie. Neste cenário, estudos com deriva simulada de 2,4-D são de singular importância para a obtenção de informações sobre a dimensão dos riscos e os níveis que espécies nativas podem tolerar ao serem exposta à deriva desse herbicida.

\section{Conclusões}

Em doses baixas o 2,4-D causa intoxicações leves e temporárias nas mudas de pequi, contudo, ocorre recuperação das plantas 15 dias após a aplicação.

As variáveis área foliar, área foliar específica e razão de área foliar das plantas apresentam hormese às doses reduzidas de 2,4-D.

O 2,4-D em maiores doses promove redução no crescimento das plantas de pequi, caracterizado pela redução das variáveis relacionadas às folhas $\mathrm{e}$ consequentemente à massa seca total das plantas.

\section{Referências}

Alves Júnior, J. et al. Respostas do pequizeiro à irrigação e adubação orgânica. Global Science Technology, v. 8, n. 1, p. 47-60, 2015.

Boutin, C. et al. Herbicide impact on non-target plant reproduction: What are the toxicological and ecological implications? Environmental Pollution, v. 185, p. 295-306, 2014. DOI: 10.1016/j. envpol.2013.10.009.

Calabrese, E. J. \& Baldwin, L. A. Applications of hormesis in toxicology, risk assessment and chemotherapeutics. Trends in Pharmacological Sciences, v. 23, n. 7, p. 331-337, 2002.

Castro, E. M. et al. Crescimento e anatomia foliar de plantas jovens de Mikania glomerata Sprengel (guaco) submetidas a diferentes fotoperíodos. Revista Ciência e Agrotecnologia, v. 27, n. 6, p. 1293 1300, 2003. DOI: 10.1590/S1413-70542003000600013. 
Cedergreen, N. et al. Chemical stress can increase crop yield. Field Crops Research, v. 114, n. 1, p. 54-57, 2009. DOI: 10.1016/j. fcr.2009.07.003.

Cedergreen, N. et al. Improved empirical models describing hormesis. Environmental Toxicology and Chemistry, v. 24, n. 12, p. 3166- 3172, 2005. DOI: 10.1897/05-014R.1.

Constantin, J. et al. Efeito de subdoses de 2,4-D na produtividade de fumo e suscetibilidade da cultura em função de seu estádio de desenvolvimento. Revista Engenharia Agrícola, v. 27, nesp., p. 30-34, 2007. DOI: 10.1590/S0100-69162007000200005.

Costa, A. G. F. et al. Efeitos de ponta de pulverização na deriva de glyphosate + 2,4-D em condições de campo. Revista Brasileira de Herbicidas, v. 11, n. 1, p. 62-70, 2012. DOI: 10.7824/rbh.v11i1.143.

Egan, J. F. et al. Herbicides drift can affect plant and arthropod communities. Agriculture, Ecosystems and Environment, v. 185, p. 77-87, 2014. DOI: 10.1016/j.agee.2013.12.017.

Fagliari, J. R. et al. Impact of sublethal doses of 2,4-D simulating drift, on tomato yield. Journal of Environmental Science and Health, v. 40, n. 1, p. 201-206, 2005. DOI: 10.1081/PFC-20003432.

Gitti, D. C. et al. Glyphosate como regulador de crescimento em arroz de terras altas. Pesquisa Agropecuária Tropical, v. 41, n. 4, p. 500-507, 2011. DOI: 10.5216/pat.v41i4.10160.

Gusmão, G. A. et al. Deriva simulada de glyphosate em plantas jovens de jenipapo (Genipa americana L.). Revista Brasileira de Herbicidas, v. 10, n. 1, p. 13-19, 2011. DOI: 10.7824/rbh.v10i1.91.

Mousdale, D. M. \& Coggins, J. R. Amino acid synthesis. In: Kirkwood, R. C. (Ed.). Target sites for herbicide action. New York: Premium Press, 1991. p. 29-56.

Oliveira Junior, R. S. et al. Efeito de subdoses de 2,4-D na produtividade de uva Itália e suscetibilidade da cultura em função de seu estádio de desenvolvimento. Revista Engenharia Agrícola, v. 27, nesp., p. 35-40, 2007. DOI: 10.1590/S0100-69162007000200006.

Oliveira, M. N. S. et al. Medição da área foliar do pequizeiro utilizando a soma da nervura principal dos folíolos. Unimontes Científica, v. 3, n. 3, p. 1-7, 2002.
Pereira, M. R. R. et al. Subdoses de glyphosate no desenvolvimento de espécies arbóreas nativas. Bioscience Journal, v. 31, n. 2, p. 326332, 2015. DOI: 10.14393/bj-v31n2a2015-21924.

Reis, T. C. et al. Efeitos de fitotoxidade do herbicida 2,4-D no milho em aplicações pré e pós-Emergência. Revista de Biologia e Ciências da Terra, v. 10, n. 1, p. 25-33, 2010.

Rodrigues, R. C. et al. Produção de massa seca, relação folha/colmo e alguns índices de crescimento de Brachiaria brizantha cv. Xaraés cultivado com a combinação de doses de nitrogênio e potássio. Revista Brasileira de Zootecnia, v. 37, n. 3, p. 394-400, 2008. DOI: 10.1590/S1516-35982008000300003.

Ronchi, C. P. et al. Effect of 2,4-dichlorophenoxyacetic acid applied as a herbicide on fruit shedding and coffee yield. Weed Research, v. 45, n. 1, p. 41-47, 2005. DOI: 10.1111/j.1365-3180.2004.00427.x.

Sá, F. V. S. et al. Produção de mudas de mamoeiro irrigadas com água salina. Revista Brasileira de Engenharia Agrícola e Ambiental, v. 17, n. 10, p. 1047-1054, 2013. DOI: 10.1590/S141543662013001000004.

Santos, F. S. et al. A cultura do Pequi (Caryocar brasiliense Camb.). Acta Iguazu, v. 2, n. 3, p. 46-57, 2013.

Sigmaplot. Scientific graphing software: version 12.0. São Jose: Systat Corporation, 2012.

Silva, F. B. Biomarcadores e potencial fitoindicador de Dipteryx alata Vogel da ação dos herbicidas 2,4-D e nicosulfuron. 2015. 56 f. Dissertação (Mestrado em Ciências Agrárias) Instituto Federal Goiano, Rio Verde.

Silva, J. C. et al. Efeito hormese de glyphosate em feijoeiro. Pesquisa Agropecuária Tropical, v. 42, n. 3, p. 295-302, 2012. DOI: 10.1590/ S1983-40632012000300008.

Soares, W. L. \& Porto, M. F. Atividade agrícola e externalidade ambiental: uma análise a partir do uso de agrotóxicos no cerrado brasileiro. Ciência \& Saúde Coletiva, v. 12, n. 1, p. 131-143, 2007. DOI: $10.1590 / \mathrm{S} 1413-81232007000100016$.

Yamashita, O. M. et al. Deriva simulada de herbicidas em mudas de Coffea canephora. Scientia Agraria Paranaensis, v. 12, n. 2, p. 148-156, 2013. 
